\title{
Estimation of Insulated-gate Bipolar Transistor Operating Temperature: Simulation and Experiment
}

\author{
Ivan Bahun ${ }^{\dagger}$, Viktor Sunde*, and Zeljko Jakopovic ${ }^{*}$ \\ ${ }^{\dagger}$ KONCAR-Electric Vehicles Inc., Zagreb, Croatia \\ ${ }^{*}$ Faculty of Electrical Engineering and Computing, University of Zagreb, Zagreb, Croatia
}

\begin{abstract}
Knowledge of a power semiconductor's operating temperature is important in circuit design and converter control. Designing appropriate circuitry that does not affect regular circuit operation during virtual junction temperature measurement at actual operating conditions is a demanding task for engineers. The proposed method enables virtual junction temperature estimation with a dedicated modified gate driver circuit based on real-time measurement of a semiconductor's quasi-threshold voltage. A simulation was conducted before the circuit was designed to verify the concept and to determine the basic properties and potential drawbacks of the proposed method.
\end{abstract}

Key words: IGBT, operating temperature measurement, threshold voltage, temperature-sensitive electrical parameter

\section{INTRODUCTION}

Temperature management and control are among the most critical functions of power electronic devices. Operating temperature and thermal cycling can seriously affect device performance and reliability. Therefore, estimating a power semiconductor's temperature or virtual junction temperature at actual operating conditions is important.

Two basic approaches are utilized to estimate operating temperature. The first approach is to develop an appropriate device thermal model that can be implemented with an actual processing computer and utilized in the estimation of virtual junction temperature. The complexity of developed thermal models varies from simple 1D models to complex 3D structures [1-6]. The second approach involves sensing the virtual junction temperature during converter operation by measuring the values of different temperature-sensitive electrical parameters (TSEPs) [7-10]. The second approach is more complex but produces more accurate results than the first approach.

The methods utilized at present to determine instantaneous

Manuscript received Sep. 4, 2012; revised Apr. 11, 2013

Recommended for publication by Associate Editor John Shen.

${ }^{\dagger}$ Corresponding Author: ivan.bahun@koncar-kev.hr

Tel: +3851-880-1760; Fax: +3851-878-1452, KONCAR-Electric

Vehicles Inc.

*Faculty of Electrical Engineering and Computing, University of Zagreb, Croatia virtual junction temperature in single power devices cannot be employed in converters operated in the field because such methods are basically quasi-static techniques. A method that allows the measurement of instantaneous virtual junction temperature without affecting converter operation in a power device operating at actual conditions must be established. This paper presents an original approach for on-line insulated-gate bipolar transistor (IGBT) virtual junction temperature measurement through simulation and experimental verification.

\section{TSEPS}

A TSEP in a power semiconductor device is an electrical parameter that can be measured and exhibits defined temperature dependence. TSEPs are utilized in indirect methods of virtual junction temperature measurement. One important property of TSEPs is that they represent the averaged temperature of a specific semiconductor area, which should not be the hottest region in the semiconductor. This averaged semiconductor temperature is often called virtual junction temperature. The selection of the most appropriate TSEP depends on the type of the device under test (DUT). A previous study [13] and literature overview [14] suggest that gate threshold voltage is the most appropriate TSEP for thermal resistance and transient thermal impedance measurements for metal-oxide semiconductor field-effect 
transistors (MOSFETs) and IGBTs. Threshold voltage as a TSEP represents the averaged channel region temperature.

Threshold voltage as a TSEP has good temperature sensitivity $(\sim 10 \mathrm{mV} / \mathrm{K})$ and represents the temperature in the hottest semiconductor region (channel region) [20].

One of the disadvantages of threshold voltage as a TSEP is that for a single device, threshold voltage depends on the gate structure and concentration of carriers; therefore, is not reproducible for different samples of the same family. This disadvantage is important in individual applications but can be solved by a simple referent measurement on one switch during converter testing.

The first step in utilizing TSEPs as a temperature indicator is TSEP calibration at defined temperatures and derivation of the calibration curve for the specified component (static TSEP calibration). The obtained calibration curves should be employed in actual operating conditions [15].

\section{IGBT THRESHOLD VOLTAGE AS A TSEP}

The threshold voltage $\left(V_{\mathrm{th}}\right)$ of IGBTs is usually the gate-emitter voltage where an inversion layer forms at the interface between the insulating layer (oxide) and the substrate (body) of the transistor. The current amplitude that should flow through the channel when the conducting path is formed has not been defined clearly. This value should be defined for calibration and measurement purposes. $V_{\text {th }}$ increases linearly with gate-oxide thickness and the square root of the p-base doping concentration. The fixed surface charge at the oxide-silicon interface and mobile ions in the oxide modify $V_{\text {th }}$ [21]. Some of the above parameters (e.g., oxide thickness, p-base doping, and oxide charge) exhibit typical statistical variations during fabrication. Consequently, the value of $V_{\text {th }}$ inevitably exhibits a spread even among transistors belonging to the same production lot. This fact has consequences in the calibration procedure as well as in the practical application of the proposed method.

\section{A. Threshold Voltage Temperature Sensitivity}

$V_{\text {th }}$ has a negative temperature coefficient of $8.6 \mathrm{mV} / \mathrm{K}$ for a specific IGBT device [17]. This value is also the typical value of $V_{\mathrm{th}}$ temperature sensitivity in conducted experiments [13].

\section{B. Calibration of Threshold Voltage Temperature Dependence}

An appropriate calibration procedure should be conducted to properly utilize threshold voltage as a TSEP. Such calibration would allow the derivation of calibration curves for the specified components within the temperature range of interest $\left(20^{\circ} \mathrm{C}\right.$ to $\left.125^{\circ} \mathrm{C}\right)$. Fig. 1 shows the typical circuit [15] for static calibration of the threshold voltage temperature dependence curve. The IGBT module was placed on the temperature-controlled board, thereby maintaining the referent temperature within the temperature range of interest.

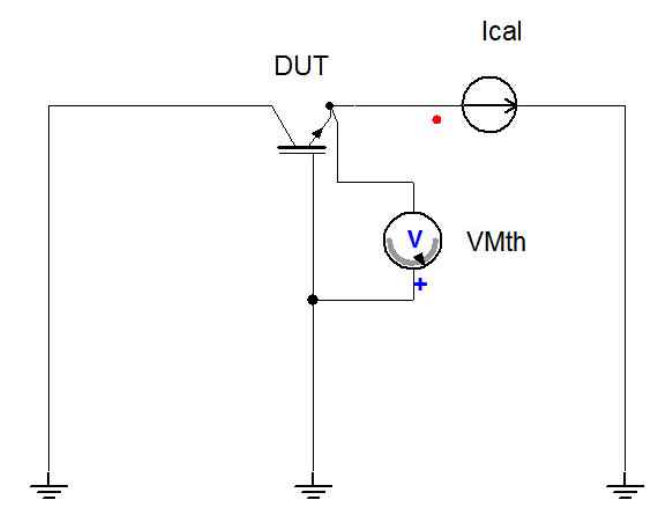

Fig. 1. IGBT threshold voltage static calibration circuit (valid for simulation and actual experiments).

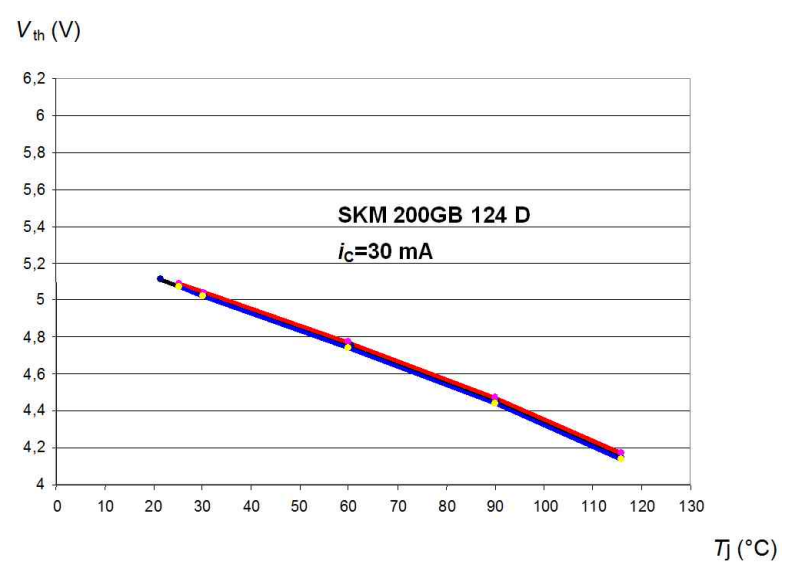

Fig. 2. Static calibration curves of IGBT threshold voltage temperature dependence for different samples of the same IGBT type (low scattering of characteristics).

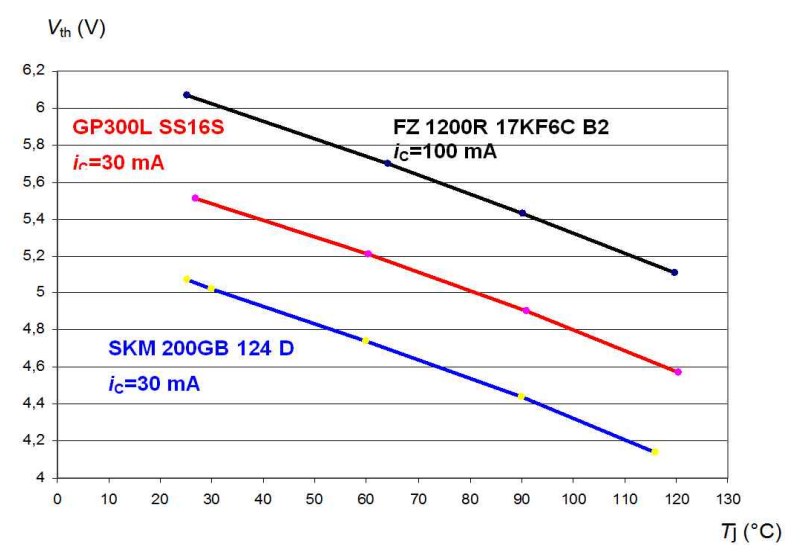

Fig. 3. Static calibration curves of IGBT threshold voltage temperature dependence for different IGBT types and manufacturer samples (typical results).

The current source $\left(I_{\mathrm{cal}}\right)$ generates the voltage $\left(V_{\mathrm{GE}}\right)$ required to form a channel. Calibration current $I_{\text {cal }}$ can be within the range of $1 \mathrm{~mA}$ to $100 \mathrm{~mA}$. No clear directives exist for the selection of calibration current. The measured $V_{\mathrm{GE}}\left(V_{\mathrm{Mth}}\right)$ at 
selected calibration current $I_{\text {cal }}$ represents $V_{\text {th }}$ at the referent temperature. Several calibration measurements were performed on various IGBT samples resulting in interesting results for the two extreme cases shown in Figs. 2 and 3.

Fig. 2 shows that the threshold voltage temperature dependence curves of different samples of the same IGBT type exhibit excellent agreement.

Fig. 3 presents the calibration curves of IGBT threshold voltage temperature dependence for different IGBT types and manufacturer samples. The difference in the temperature sensitivity coefficient values between the two classes of IGBTs is caused by the technology of the semiconductor device. The typical value of temperature sensitivity coefficient $k_{\mathrm{T}}$ is $-10 \mathrm{mV} / \mathrm{K}$ for IGBT modules and approximately $-8 \mathrm{mV} / \mathrm{K}$ for small IGBTs.

Different calibration current values were observed during calibration. Given that no standard values for $I_{\text {cal }}$ are defined in literature, our experiment included several different $I_{\text {cal }}$ values. However, comparison of the results was conducted based on the same $I_{\text {cal }}$ value. The $I_{\text {cal }}$ values utilized for the selected device resulted in similar temperature sensitivity coefficient $k_{\mathrm{T}}$ but different nominal threshold voltage values $V_{\text {th0 }}$.

Threshold voltage temperature dependence is obviously linear in the temperature region of interest. When temperature sensitivity coefficient $k_{\mathrm{T}}$ and nominal threshold voltage $V_{\text {th0 }}$ are known (from the static calibration curve) for each DUT, a simple expression enables the interpolation of semiconductor virtual junction temperature $T_{\mathrm{J}}$ based on the measured threshold voltage $V_{\text {thM }}$.

$$
V_{\mathrm{thM}}\left(T_{\mathrm{J}}\right)=V_{\mathrm{th} 0}-k_{\mathrm{T}}\left(T_{\mathrm{J}}-T_{0}\right)
$$

The use of catalogue data for the calculation of nominal threshold voltage $V_{\text {tho }}$ is not advisable because of sample data scattering as noticed during static calibration. Sample data scattering can result in large estimated temperature errors. Proper threshold voltage application as a TSEP requires that threshold voltage be measured at similar conditions during the

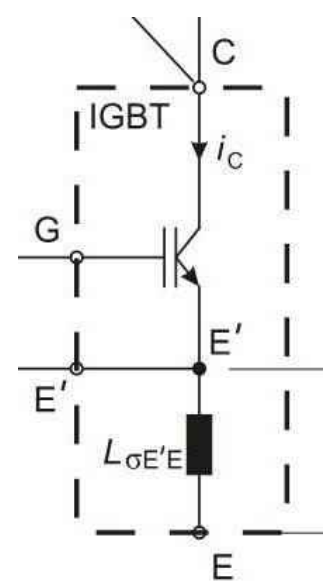

Fig. 4. Parasitic inductance $L_{\sigma \mathrm{E}}$ of an IGBT module. calibration and measurement phase. The proposed measurement method therefore requires a dedicated, slightly modified threshold voltage calibration procedure. However, the fundamental properties of threshold voltage and its temperature dependence and temperature sensitivity coefficient must remain the same.

\section{OPERATING TEMPERATURE MEASUREMENTS WITH THRESHOLD VOLTAGE AS A TSEP}

Threshold voltage measurement for MOSFETs and IGBTs is a very sensitive procedure because it includes switching in the gate control circuit. No known methods involve standard threshold voltage measurement for standard power electronic circuits at actual operating conditions, not even for a simple one such as a chopper. An event that clearly indicates the start of the increase in IGBT collector current could be of help.

\section{A. Quasi-threshold Voltage Concept}

IGBT module construction has parasitic elements such as parasitic inductance $L_{\sigma \mathrm{E}}$ between the emitter control and power connections E' and E as shown in Fig. 4.

A small but measurable voltage induced on parasitic inductance $L_{\sigma \mathrm{E}}\left(v_{\mathrm{L \sigma E}}\right)$ was observed during an increase in collector current $i_{\mathrm{C}}$ as shown in Fig. 5. If this voltage is measured precisely with correct timing, the start of the $v_{\mathrm{L \sigma E}}$ pulse could define IGBT threshold voltage precisely. Considering that this voltage is not threshold voltage according to definition, the term quasi-threshold voltage is used instead. The properties of quasi-threshold voltage and how different circuit parameters and measurement conditions influence the ability of quasi-threshold voltage to estimate on-line IGBT operating temperature with satisfactory precision are unknown. Conducting a simulation prior to constructing a complex gate driver that would enable the measurement of quasi-threshold voltage is therefore useful. A simulation was conducted in this study with an appropriate simulation software that enables the electrothermal simulation of power semiconductor devices.

\section{SIMULATION}

A simulation was conducted to test the calibration and measurement phase in IGBT operating temperature estimation with quasi-threshold voltage as well as to investigate the basic properties of the proposed method. The simulation was performed with standard electrical circuit simulation software SIMPLORER V7. This program can run electrothermal simulations and generate complex semiconductor electrothermal models.

\section{A. Electrothermal Simulation Principle}

The fundamental property of electrothermal simulations is the simultaneous calculation of the electrical and thermal 


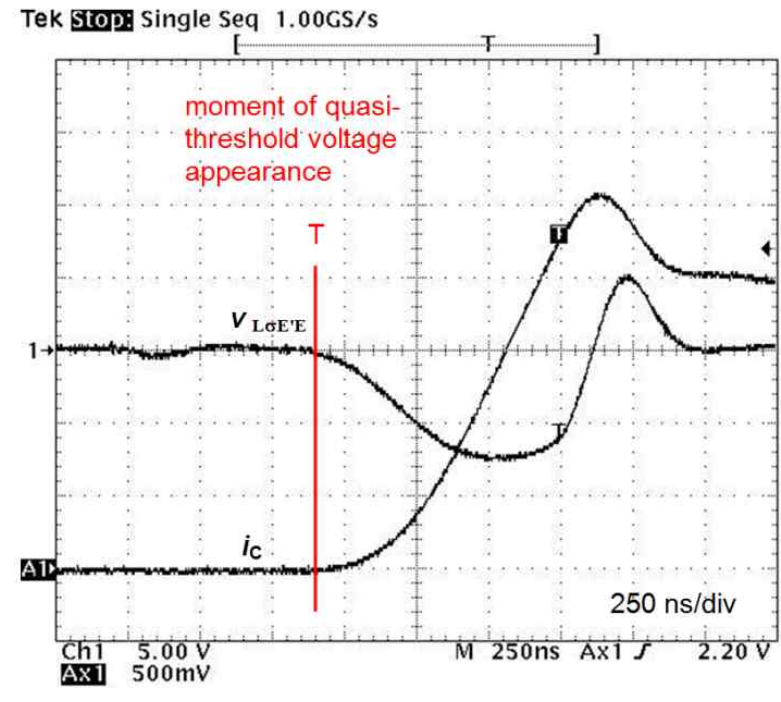

Fig. 5. Waveforms of collector current $\left(i_{\mathrm{C}}, 250 \mathrm{~A} / \mathrm{div}\right)$ and parasitic inductance voltage (inverted, $-v_{\mathrm{L \sigma E}}, 2 \mathrm{~V} / \mathrm{div}$ ) during the IGBT turn-on phase. T marks the moment when quasi-threshold voltage appears. Measured with an actual circuit as that in Fig. 7.

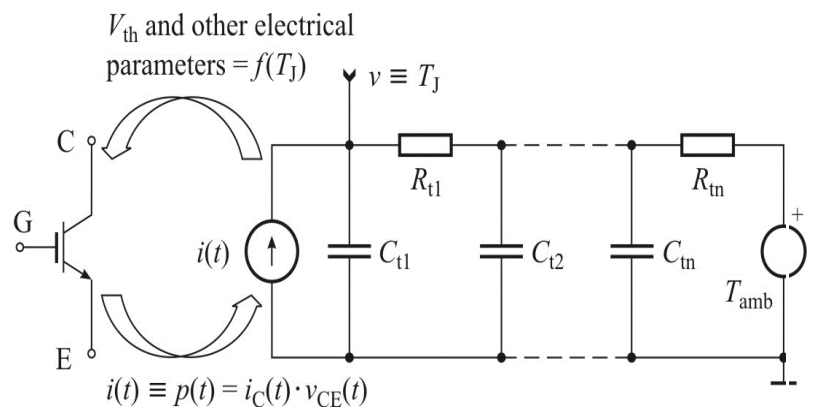

Fig. 6. Electrothermal simulation model.

variables required for the accurate description of a semiconductor's electrothermal behavior (Fig. 6) [6]. The electrical part of the semiconductor model calculates developed electrical power $p(t)$ based on temperature-dependent dynamic semiconductor equations. The thermal part of the semiconductor model continuously calculates junction temperature $T_{\mathrm{J}}(t)$ based on dissipated power $p(t)$ and applied equivalent thermal model with appropriate thermal resistance and capacitance values. An equivalent Cauer network is normally utilized because such network is suitable for combining thermal systems (e.g., adding a heat sink to the semiconductor) [18]. Although a simple electrothermal simulation is not appropriate for extremely short current pulses [19], satisfactory results are expected from cases of normal loading (such as the case in this study).

The IGBT model parameters that define threshold voltage temperature-dependent behavior were tuned based on the simulation experiment shown in Fig. 1. Threshold voltage temperature coefficient value was set to $8.7 \mathrm{mV} / \mathrm{K}$, which is a typical parameter value for large IGBTs.

\section{B. Simulation of the Two-Pulse Method}

Two-pulse method was utilized to provide almost-real IGBT turn-on and turn-off conditions at nominal voltage and current with negligible semiconductor temperature increase during the experiment. The simulation should prove that this condition is achieved. The circuit shown in Fig. 7 was utilized in the simulation as well as in the actual experiment. The component values were selected to ensure nominal operating voltages and currents.

The two-pulse method principle is as follows: during the first pulse, the IGBT current increases linearly from zero to a nominal value at $100 \mu$ s time interval. After achieving the nominal value, IGBT turn-off ensues with a $10 \mu$ s pause when the nominal current flows through a freewheeling diode. The IGBT turns on a nominal current with a $20 \mu$ s on-time interval after the pause.

Fig. 8 shows the characteristic waveforms obtained during the simulation. The junction temperature waveform in Fig. 8(B) shows that even at $1000 \mathrm{~A}$ current level, the internal IGBT temperature increase during the two-pulse method experiment does not exceed $0.3 \mathrm{~K}$. This finding confirms that a negligible semiconductor temperature increase occurred during the experiment. The most important instant in the two-pulse method experiment occurred at approximately $110 \mu \mathrm{s}$, at the beginning of the nominal current increase, when the quasi-threshold voltage was measured.

Fig. 9 shows the characteristic simulation waveforms for quasi-threshold voltage measurement during the two-pulse method experiment. Parasitic voltage $v_{\mathrm{L \sigma E}}$ occurred at the beginning of the collector current increase, representing the formation of the conducting channel. This occurrence served as a trigger for IGBT gate voltage $v_{\mathrm{GE}}$ measurement. Quasi-threshold voltage was then measured.

\section{Simulation of Quasi-Threshold Voltage Method}

After the simulative calibration of the IGBT electrothermal model and simulative verification of the two-pulse method, the properties and sensitivity of the proposed quasi-threshold voltage method were examined next. The IGBT turns on different levels of collector currents with different derivations at actual operating conditions. The quasi-threshold detection level could differ because of circuit noise. These effects, including measurement chain delay, can significantly influence the accuracy of the proposed method. Verifying the influence of the aforementioned effects on the proposed method's accuracy through experimentation is difficult given that our experiment is time consuming. Simulative investigation is a good solution to speed up the procedure.

The influence of collector current amplitude $I_{\mathrm{C}}$ on measured quasi-threshold voltage $V_{\text {Qth }}$ was examined first. Next, the 


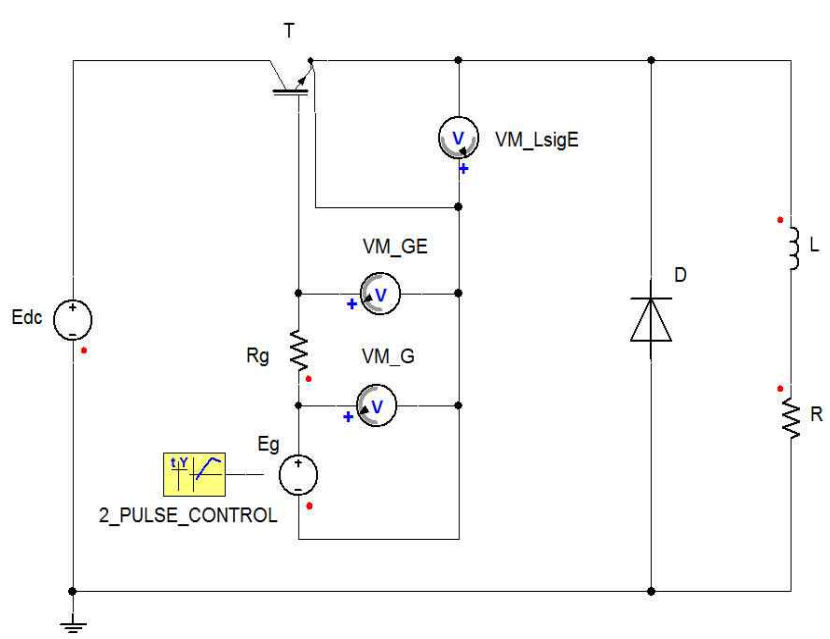

Fig. 7. Two-pulse method schematic (valid for simulation and actual experiments).

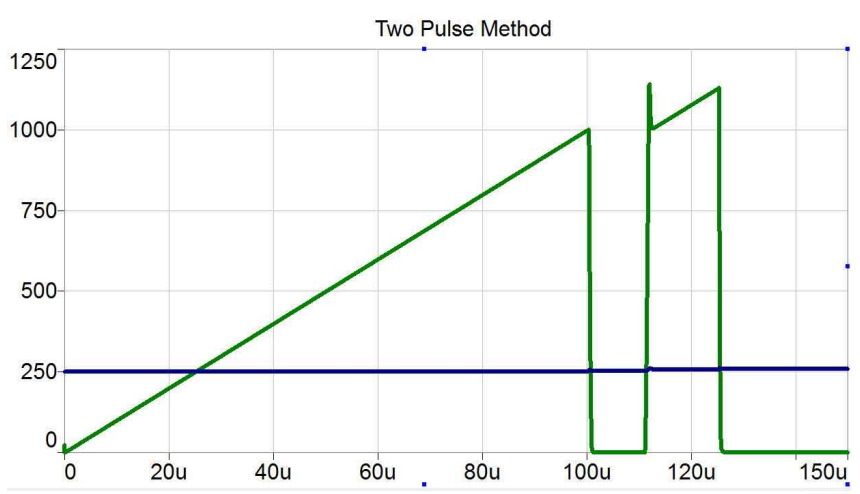

Fig. 8. Characteristic simulation waveforms of two-pulse method.

A - IGBT collector current (A, scale x 1)

$\mathrm{B}-$ IGBT junction temperature $\left({ }^{\circ} \mathrm{C}\right.$, scale $\left.\mathrm{x} 10\right)$

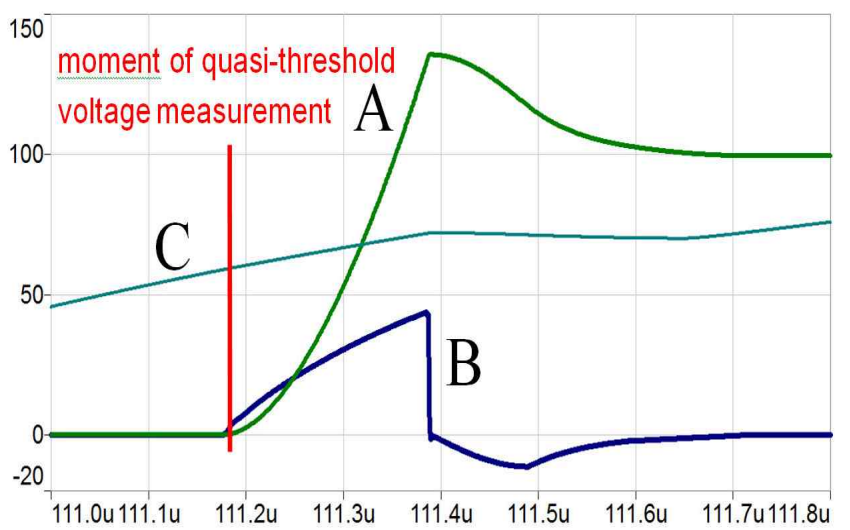

Fig. 9. Characteristic simulation waveforms for quasi-threshold voltage measurement with two-pulse method.

A - IGBT collector current $I_{\mathrm{C}}(\mathrm{A}$, scale x 0.1)

$\mathrm{B}$ - parasitic voltage $v_{\mathrm{LoE}}(\mathrm{V}$, scale $\mathrm{x} 10)$

$\mathrm{C}-$ IGBT gate voltage $v_{\mathrm{GE}}(\mathrm{V}$, scale $\mathrm{x} 10)$
1) Influence of collector current amplitude: IGBT collector current $I_{\mathrm{C}}$ is controlled by supply voltage $E_{\mathrm{dc}}$. In the experiment, $I_{\mathrm{C}}$ varied from $100 \mathrm{~A}$ to $1000 \mathrm{~A}$ at a temperature of $T_{\mathrm{J}}=25^{\circ} \mathrm{C}$. The nominal value of quasi-threshold voltage $V_{\mathrm{Qth}}$ at $I_{\mathrm{C}}=$ $1000 \mathrm{~A}$ is $5.926 \mathrm{~V}$.

The largest change in measured $V_{\text {Qth }}$ during the experiment is $\Delta V_{\text {Qth }}=10 \mathrm{mV}$, indicating that temperature change $\Delta \mathrm{T} \approx 1 \mathrm{~K}$. This temperature change is practically negligible.

2) Influence of collector current derivation: The derivation of IGBT collector current during turn-on $\mathrm{d} I_{\mathrm{C}} / \mathrm{d} t$ is controlled by gate resistor value $R_{\mathrm{G}}$. The obtained $\Delta V_{\mathrm{Qth}}$ is $5 \mathrm{mV}$ at maximum for different derivation values with the same $I_{\mathrm{C}}$ value, indicating that temperature change $\Delta \mathrm{T} \approx 0.5 \mathrm{~K}$. This temperature change is also practically negligible.

3) Influence of $v_{\mathrm{L} \sigma \mathrm{E}}$ detection level: Sampling gate voltage $v_{\mathrm{GE}}$ at the lowest possible $v_{\mathrm{L \sigma E}}$ value is obviously appropriate. However, the achievable values for $v_{\mathrm{L \sigma E}}$ detection levels are from $25 \mathrm{mV}$ to $50 \mathrm{mV}$. In this experiment, $I_{\mathrm{C}}$ varies from $100 \mathrm{~A}$ to $1000 \mathrm{~A}$. The $v_{\mathrm{L \sigma E}}$ detection level varies from $25 \mathrm{mV}$ to $150 \mathrm{mV}$. The maximum change in voltage detection level resulted in a variation in voltage detection time of $\Delta t=5 \mathrm{~ns}$ and a variation in the measured quasi-threshold voltage of $\Delta V_{\text {Qth }}=$ $33 \mathrm{mV}$, resulting in a change in the estimated junction temperature of $\Delta \mathrm{T} \approx 3.5 \mathrm{~K}$. This change in estimated junction temperature is barely acceptable. Maintaining the lowest possible voltage detection level during the experiment is important.

4) Influence of measurement chain delay: Actual measurement equipment always generates measurement delays. The last part of the experiment revealed the significant influence of voltage detection time variation. In the simulation, delays were introduced in $v_{\mathrm{L} \sigma \mathrm{E}}$ detection time from $0 \mathrm{~ns}$ to $30 \mathrm{~ns}$. The results are striking. A detection delay of $10 \mathrm{~ns}$ results in $\Delta V_{\text {Qth }}=$ $32 \mathrm{mV}$, yielding a temperature estimation error of $\Delta \mathrm{T} \approx 7 \mathrm{~K}$. This estimation error value is unacceptable. The influence of measurement chain delay is extremely serious. However, because the error is systematic, it can be compensated for. The correction procedure should involve the following steps: measuring the derivation of $v_{\mathrm{GE}}$ at the quasi-threshold voltage instant, estimating the actual measurement circuit delay, and compensating for the numerically introduced error.

\section{ModifiEd GATE Driver CIRCUIT}

The actual experiment was conducted after the simulative verification of the quasi-threshold method principle and examination of the method's sensitivity to the influence of different effects. A modified gate driver circuit was developed (shown in Fig. 10) to apply the proposed method in indirect virtual junction temperature measurement with quasi-threshold voltage. The dedicated circuit can be employed as an add-on 


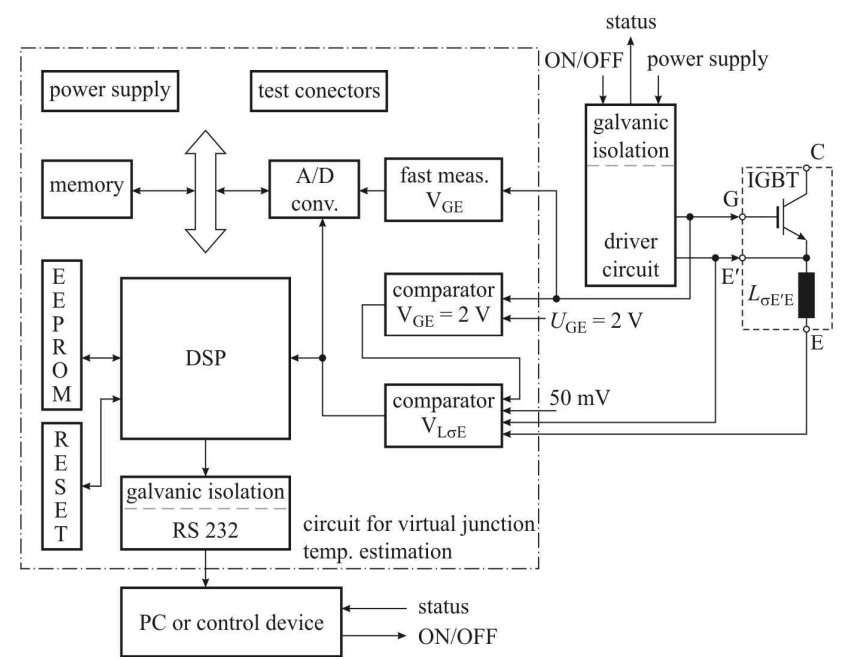

Fig. 10. Block diagram of the modified gate driver circuit for indirect virtual junction temperature measurement with quasi-threshold voltage at actual operating conditions.

unit for the existing gate driver circuit or as an integral part of the gate driver circuit. Considering the symmetrical construction and operation in the bridge circuits, the modified driver was not implemented on each power switch. The modified driver has two comparators. Comparator $V_{\mathrm{L \sigma E}}$ captures the moment of quasi-threshold voltage appearance. Comparator $V_{\mathrm{GE}}=2 \mathrm{~V}$ eliminates non-representative signals from voltage $v_{\mathrm{L} \sigma \mathrm{E}}$. Measured voltage $v_{\mathrm{GE}}=v_{\mathrm{Qth}}$ was digitized and memorized. A TMS 320 F 240 processor was utilized.

\section{ACTUAL EXPERIMENT}

A power electronic circuit was employed in the experiment as a simple buck converter with a highly inductive load (Fig. 7). The two-pulse method was selected for DUT loading. This method of power loading causes a minimal DUT temperature increase during load current $I_{\mathrm{L}}$ increase and provides realistic IGBT turn-on and turn-off conditions as verified through the simulation. Given that the semiconductor is mounted on a temperature-controlled board with resistive heaters, the temperature of the semiconductor was maintained at an almost-constant level during the experiment. The board and IGBT case temperatures were measured with thermocouples.

Quasi-threshold voltage was measured with modified gate driver circuitry at the beginning of the second power pulse when the load current reached its desired nominal value. An EUPEC FZ 1200R 17KF6C B2 IGBT was utilized as a DUT for real-time temperature measurements.

Other types of loading (e.g. PWM) can be utilized with the same modified driver to enable temperature estimation at actual operating conditions. A constant and known IGBT temperature is required during the experiment because no other independent means for temperature verification is

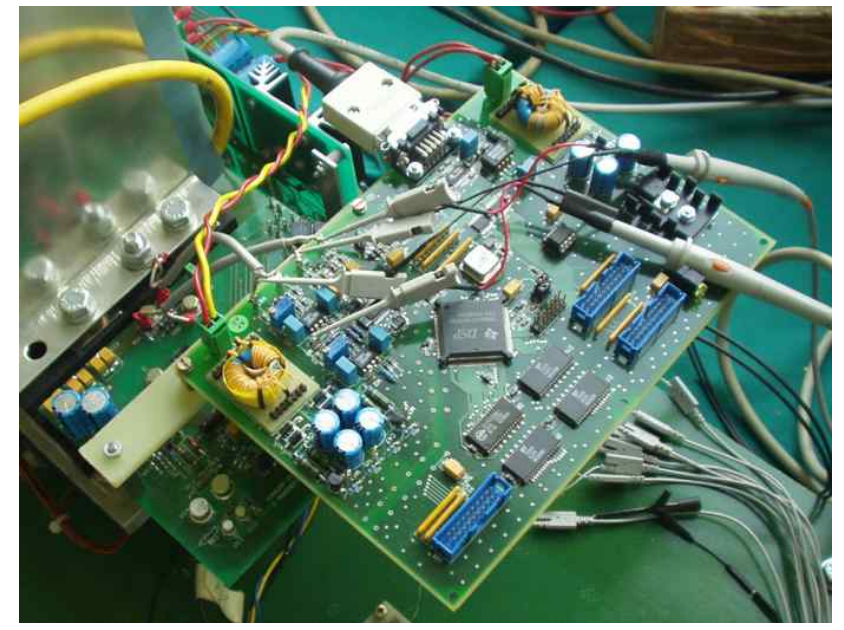

Fig. 11. Photo of the modified gate driver circuit for indirect virtual junction temperature measurement with quasi-threshold voltage at actual operating conditions.

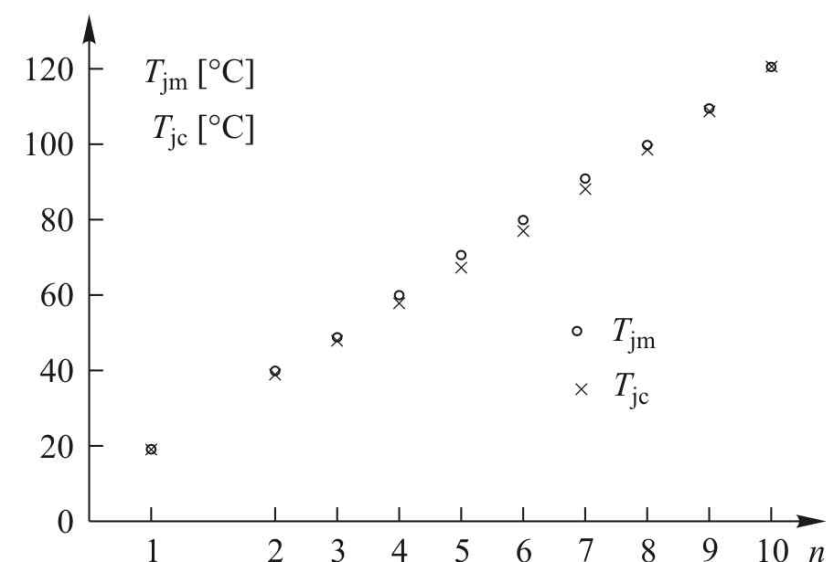

Fig. 12. Semiconductor temperature measured with a thermocouple $\left(\mathrm{x}, T_{\mathrm{ic}}\right)$ and through quasi-threshold method $(\mathrm{o}$, $\left.T_{\text {im }}\right)$.

available. Therefore, we are currently limited to the use of the two-pulse method.

\section{A. Quasi-threshold Voltage Calibration}

Actual measurement requires appropriate quasi-threshold voltage calibration at the same conditions as in the operation. Given that quasi-threshold voltage temperature sensitivity is expected to exhibit the same properties as classic threshold voltage, calibration at only two temperature points is performed. The two temperature points are room temperature $T_{0}=19.1^{\circ} \mathrm{C}$ and high temperature of $T_{\mathrm{M}}=120.5^{\circ} \mathrm{C}$. Quasi-threshold voltage was measured with two-pulse method at both temperature points. The stationary temperature of the temperature-controlled board was measured with thermocouples, and quasi-threshold voltage was measured with the modified gate driver circuitry. Nominal quasi-threshold voltage $V_{Q \mathrm{th} 0}$ at room temperature has a value of $V_{Q \mathrm{th} 0}=$ $6.909 \mathrm{~V}$; the value is $T_{\mathrm{M}}=120.5^{\circ} \mathrm{C}$ at high temperature. 
TABLE I

Two-pulse Method ExPERIMENT Results

\begin{tabular}{|l|c|c|c|c|c|c|c|c|c|c|}
\hline$T_{\mathrm{j}}\left[{ }^{\circ} \mathrm{C}\right]$ thermocouple & 19.1 & 39.9 & 49.7 & 60 & 70.6 & 79.9 & 90.9 & 99.8 & 109.5 & 120.5 \\
\hline$v_{\mathrm{GE}}=v_{\mathrm{Qth}}[\mathrm{V}]$ meas. & 6.909 & 6.736 & 6.648 & 6.571 & 6.489 & 6.403 & 6.306 & 6.215 & 6.126 & 6.021 \\
\hline$T_{\mathrm{j}}\left[{ }^{\circ} \mathrm{C}\right]$ calculated from $(1)$ & 19.1 & 38.9 & 49 & 57.8 & 67.2 & 77 & 88.1 & 98.5 & 108.6 & 120.5 \\
\hline Measurement error $\varepsilon[\%]$ & 0 & 2.5 & 1.4 & 3.6 & 4.8 & 3.6 & 3.1 & 1.3 & 0.8 & 0 \\
\hline
\end{tabular}

Quasi-threshold voltage $V_{Q \text { thM }}$ is $6.021 \mathrm{~V}$, resulting in a difference of $\Delta V_{\mathrm{Th}}=0.888 \mathrm{~V}$. The appropriate temperature sensitivity coefficient $\left(k_{\mathrm{T}}\right)$ is $-8.76 \mathrm{mV} / \mathrm{K}$. The obtained calibration results are shaded in grey in Table I.

\section{B. Conducting the Actual Experiment}

After determining the quasi-threshold voltage calibration boundary values (at minimum and maximum temperatures) of the quasi-threshold voltages, quasi-threshold voltage temperature sensitivity coefficient $k_{\mathrm{T}}$ was calculated from the quasi-threshold voltage boundary values. The temperature of the temperature-controlled board (also IGBT temperature) was set to several known values (measured with thermocouples) between minimum and maximum boundary temperatures in $n$ steps ( $n=8$ in Table I). IGBT temperature was estimated through quasi-threshold voltage method during two-pulse loading at each of the temperature points based on the relations defined in (1). The difference between semiconductor temperature measured with a thermocouple and semiconductor temperature measured through the quasi-threshold method represents the measurement method error, which should not exceed $5 \%$ to be acceptable. The measurement results in Table I (as well as in Fig. 12) confirm the expectations for the proposed method. The first row represents the heat sink temperatures measured with a thermocouple at 10 points. Considering that stationary state is maintained, the semiconductor junction temperature is equal to the heat sink temperature. The first and last column values (shaded in grey) are the boundary values obtained during calibration. The second row contains the measured quasi-threshold voltage values utilized to calculate the semiconductor temperatures in the third row. The fourth row shows the relative temperature estimation error. Relative temperature estimation error was always positive in the experiment and always resulted in a lower estimated temperature than the actual temperature measured with thermocouples. This finding indicates that measurement error can be partially compensated by utilizing the correction procedure described in chapter V.C.4. Table I is presented graphically in Fig. 12 for better visualization of the experiment results.

\section{CONCLUSIONS}

A new method that is appropriate for the estimation of power semiconductor virtual junction temperatures at actual operating conditions was proposed in this paper. The proposed method measures quasi-threshold voltage instead of classic threshold voltage, which is extremely difficult to measure at actual operating conditions.

IGBT operating virtual junction temperature was estimated based on the voltage induced on the IGBT module parasitic gate during collector current increase. When properly measured, this induced voltage indicates the moment when the conducting channel was formed; the measured gate voltage at the moment defined by the measured induced voltage is called quasi-threshold voltage.

Prior to performing the actual experiment, the fundamental properties of the proposed method were examined through a simulation and with a semiconductor electrothermal model built in a commercial electrical circuit simulator. A new modified IGBT gate driver circuit was developed. The circuit is capable of performing fast gate voltage measurement. The experiment was conducted with a temperature-controlled board and two-pulse loading method, thereby providing almost-real IGBT switch-on and switch-off conditions. The experiment results show that the proposed method is accurate enough to be utilized for power semiconductor virtual junction temperature estimation at actual operating conditions, with a maximum relative error of $5 \%$ obtainable in the regular temperature operating region. The relative measurement error can further be diminished with proper compensation. Given that the driver circuit is relatively complex, the method is probably limited to application in high power, expensive converter circuits.

\section{REFERENCES}

[1] V. Blasko, R. Lukaszewski and R. Sladky, "on line thermal model and thermal management strategy of a three phase voltage source inverter," in Conference Record of IEEE Industry Applications Society Annual Meeting, pp. 1423-1431, Oct. 1999.

[2] A. Ammous, S. Ghedira and B. Allard, "Choosing a thermal model for electrothermal simulation of power semiconductor devices," IEEE Trans. Power Electron., Vol. 14, No. 2, pp. 300-307, Mar. 1999.

[3] A. Ammous, B. Allard, and H. Morel, "Transient temperature measurements and modeling of IGBTs under short circuit," IEEE Trans. Power Electron., Vol. 13, No. 1, pp. 12-25, Jan. 1998.

[4] R. Krummer, T. Reimann, G. Berger, J. Petzoldt, and L. Lorenz, "On-line calculation of the chip temperature of power modules in voltage source converters using the microcontroller," in EPE Conf. Rec., Sep. 1999.

[5] Z. Bencic, V. Sunde, and Z. Jakopovic, "Estimation error of semiconductor devices virtual junction temperature in 
IEC's approximate formula," Automatika, Vol. 41, No. 3-4, pp. 153-157, 2000.

[6] Z. Jakopovic, V. Sunde and Z. Bencic, "Electro-thermal modelling and simulation of a power MOSFET," Automatika, Vol. 42, No. 1-2, pp. 71-77, 2001.

[7] D. Barlini, M. Ciappa, A. Castellazzi, M. Mermet-Guyennet, and W. Fichtner, "New technique for the measurement of the static and of the transient junction temperature in IGBT devices under operating conditions," Microelectronics Reliability, Vol. 46, pp. 1772-1777, 2006.

[8] D. Barlini, M. Ciappa, M. Mermet-Guyennet, and W. Fichtner, "Measurement of the transient junction temperature in MOSFET devices under operating conditions," Microelectronics Reliability, Vol. 47, pp. 1707-1712, 2007.

[9] H. Chen, V. Pickert, D. Atkinson, and L. Pritchard, "On-line monitoring of the MOSFET device junction temperature by computation of the threshold voltage," in PEMD Conf. Rec., pp. 440-444, Apr. 2006.

[10] Y.-S. Kim and S.-K. Sul, "On-line estimation of IGBT junction temperature using on-state voltage drop," in IAS Conf. Rec., pp. 853-859, Oct. 1998.

[11] H. Kuhn and A. Mertens, "On-line junction temperature measurement of IGBTs based on temperature sensitive electrical parameters," in EPE 2009 Conf. Rec., pp. 1-10, Sep. 2009.

[12] A. Bryant, P. Mawby, and P. Tavner, "Investigation into IGBT $\mathrm{dV} / \mathrm{dt}$ during turn-off and its temperature dependence," IEEE Trans. Power Electron., Vol. 26, No. 10, pp. 3012-3031, Oct. 2011.

[13] Z. Jakopovic, Z. Bencic, and F. Kolonic, "Important properties of transient thermal impedance for MOS-gated power semiconductors," in ISIE 1999 Conf. Rec., pp. 574-578, Jul. 1999.

[14] E. Farjah, C. Schaeffer, L. L. Rouve, and R. Perret, "Thermal characterization of MOS-controlled device in transient conditions," EPE Journal, Vol. 4, No. 2, pp. 33-37, Jun. 1994.

[15] D. L. Blackburn, "A review of thermal characterisation of power transistors," in SEMITHERM 1988 Conf. Rec., pp. 1-7, Feb. 1988.

[16] S.M. Sze, Physics of Semiconductor Devices, New York: J. Wiley \& Sons, 1981.

[17] A. Castellazzi, M. Ciappa, W. Fichtner, M. Piton, and M. Mermet-Guyennet, "A study of the threshold-voltage suitability as an application-related reliability indicator for planar-gate non-punch-through IGBTs," Microelectronics Reliability, Vol. 47, pp. 1713-1718, 2007.

[18] Y. C. Gerstenmaier, W. Kiffe and G. Wachutka, "Combination of thermal subsystems modeled by rapid circuit transformation," in THERMINIC 2007 CD Conf. Rec., pp. 1-6, Sep. 2007.

[19] S. Clemente, "Transient thermal response of power semiconductors to short power pulses," IEEE Trans. Power Electron., Vol. 8, No. 4, pp. 337-341, Oct. 1993.

[20] L. Dupont, Y. Avenas, and P. Jeanin " Comparison of junction temperature evaluations in a power IGBT module using an IR camera and three thermo-sensitive electrical parameters," in Applied Power Electronics Conference and Exposition, 2012 twenty-seventh annual IEEE, pp. 182-189, Feb. 2012.
[21] M. H. Rashid, Power electronics handbook: devices, circuits and applications handbook, Third Edition, Elsevier Inc, 2011.

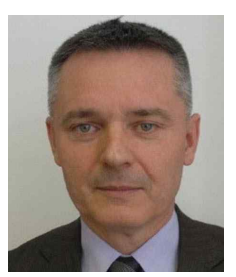

Ivan Bahun was born in Cerje Nebojse, Croatia, in 1960. He received his B.S.E.E., M.S.E.E., and Ph.D.E.E. degrees from the Faculty of Electrical Engineering and Computing, University of Zagreb, in 1984, 1992, and 2005, respectively. He is currently the President of the Managing Board of Končar-Electric Vehicles Inc. His areas of interest are tram, train, and electric locomotives and new power electronic solutions for electric vehicles. He has been the author and coauthor of manuscripts published in journals and presented at national and international conferences. $\mathrm{He}$ is a member of Korema.

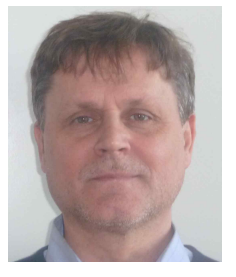

Viktor Sunde was born in Orah, Vrgorac, Croatia, on April 4, 1959. He received his B.S. and M.S. degrees from the Faculty of Electrical Engineering, University of Zagreb, in 1984 and 1992, respectively. He received his Ph.D. degree from the Faculty of Electrical Engineering and Computing, University of Zagreb, in 1999. He has been an associate professor at the Faculty of Electrical Engineering and Computing, University of Zagreb, since 2011. He is the author and coauthor of several manuscripts published in scientific journals and presented in the proceedings of international and domestic conferences. His research interests include power electronics, technology of electronic and electrical components, and modeling and simulation of power electronic systems.

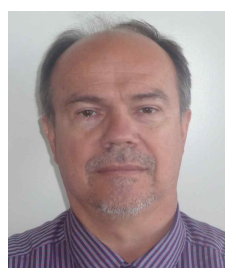

Zeljko Jakopovic was born in Zagreb, Croatia, in 1959 . He received his B.S.E.E., M.S.E.E., and Ph.D.E.E. degrees from the Faculty of Electrical Engineering and Computing, University of Zagreb, in 1981, 1992, and 1997, respectively. He is currently a professor at the Faculty of Electrical Engineering and Computing, University of Zagreb. His areas of interest are modelling and simulation in power electronics, active power factor correction, and converter control techniques as well as introduction of modern power electronic education methods. He has been the author and coauthor of numerous manuscripts published in journals and presented at national and international conferences. He is a member of Korema and IEEE (PEL, IA). 